\title{
Corpografías divergentes: las ciudades deseadas y las prohibidas en las experiencias travestis (Brasil)
}

\author{
Diverging Corpographies: Desired and \\ Prohibited Cities in Transvestite Experiences (Brazil)
}

DOI: $10.22380 / 2539472 X .800$

Silvana de Souza Nascimento*

Universidade de São Paulo, Brasil

\begin{abstract}
RESUMEN
Mediante pesquisas etnográficas realizadas en dos regiones de Brasil — São Paulo y Paraíba-, este artículo reflexiona sobre las maneras en que travestis y mujeres transexuales se hacen presentes en distintos espacios urbanos y cómo construyen formas de resistencia ante las adversidades de los modelos de la ciudad moderna y las violencias de las que son víctimas. Su presencia en calles, avenidas, aceras y plazas de los medios urbanos no solo desafía reglas heteronormativas, sino ideas de espacio público, prácticas sexuales, corporeidades y géneros. A partir de experiencias urbanas diversas, hay un proyecto de transformación corporal y de movilidad social común que se inscribe en una imbricación intensiva entre cuerpo trans y ciudad, produciendo procesos de desterritorialización y reterritorialización.
\end{abstract}

Palabras clave: cuerpo, travesti, mujer transexual, prostitución, ciudad.

\begin{abstract}
$\overline{\text { ABSTRACT }}$
Based on ethnographic research in two regions of Brazil — São Paulo and Paraíba-, this article reflects on how transvestite and transexual women (MTF - male to female) are present in different urban spaces and how they build forms of resistance in face of the adversities of modern city models and the violences of which they are victims. Their presence on streets, avenues, sidewalks, and squares in urban environments not only contests heteronormative rules but notions of public space, sexual practices, corporalities, and gender. From diverse urban experiences, there is a common project of corporal transformation and social mobility inscribed in an intensive imbrication of trans body and city, producing processes of deterritorialization and reterritorialization.
\end{abstract}

Keywords: Body, "travesti", transexual woman, prostitution, city.

Doctora en Antropología de la Universidade de São Paulo. Profesora del Departamento de Antropología da FFLCH e investigadora del Laboratório do Núcleo de Antropología Urbana de la misma universidad. silnasc@usp.br / https://orcid.org/0000-0001-5661-4915 
Dar placer fue mi destino amargo, dar, pero también recibir.

$Y$ si sentir placer en aquello con que se trabaja es criterio para elegir profesión, la mía ya está elegida. ¿Y si yo fuera puta? Ahora lo era. (Amara Moira, Se eu fosse puta, 2016)

ste artículo ${ }^{1}$ busca reflexionar, por medio de investigaciones etnográficas realizadas en diferentes regiones de Brasil, sobre las maneras en que travestis y mujeres transexuales ${ }^{2}$ se hacen presentes en distintos espacios urbanos y cómo construyen formas de resistencia y de vida que desafían nociones de espacio público, prácticas sexuales, corporeidades y género. Es decir, cómo travestis y mujeres transexuales brasileñas, que trabajan en la prostitución de calle, producen nociones de corporeidad - como locus de la existencia y como fuente de la experiencia (Csordas 2013)—, que no se circunscriben a los modelos dualistas del masculino y del femenino cisgénero ${ }^{3} \mathrm{y}$, por esta razón, son susceptibles de ser juzgadas, condenadas, subyugadas y violentadas.

A pesar de la reciente ampliación de los derechos humanos de lesbianas, gais, bisexuales, travestis y transexuales (LGBT), Brasil es el país con la mayor tasa de homicidios de personas LGBT del mundo y, en especial, de personas trans (travestis, mujeres transexuales, hombres trans y no binarias). Según un informe del Grupo Gay da Bahia, una de las asociaciones brasileñas más antiguas de defensa de homosexuales, 343 personas LGBT fueron asesinadas en Brasil en el 2016, lo que significa un homicidio cada 25 horas. De estas, 144 eran trans ${ }^{4}$.

1 Traducción del portugués por Zenaide Romanovsky.

2 Utilizaré aquí los términos emic travestis y mujeres transexuales para referirme a categorías prácticas de reconocimiento (García 2009) que involucran a personas que rechazan la identidad de género masculina y buscan construir identidades de género femeninas. Esas dos categorías no se distinguen por el hecho de que la segunda se refiera solo a quienes se hicieron cirugías de reasignación sexual. Dependen, antes que nada, de una autoidentificación que incluye subjetividades, historias de vida, marcadores de clase y raza y posiciones políticas.

3 La expresión cisgénero ha sido utilizada en los últimos años en Brasil por los movimientos trans para diferenciar las identidades de género en las cuales convergen el "sexo biológico" - designado al nacer por la medicina - y la identidad de género, de aquellas en las cuales estos son divergentes. De forma simplificada, la expresión cis significa el opuesto de trans. Esta dualidad ha provocado muchas controversias y discusiones políticas y académicas, que no se explorarán aquí.

4 Según investigaciones de la organización Transgender Europe (TGEU), de octubre del 2015 a noviembre del 2016 se registraron 295 casos de homicidio de personas trans a escala mundial. Los datos muestran que Brasil se encuentra en el primer lugar con 123 muertes, seguido por México con 52, Estados Unidos con 23 y Colombia con 14 (https://tgeu.org/tdor-2016-pressrelease). Es importante señalar que hay un gran desfase de información estadística sobre la violencia hacia la población trans en Brasil. Generalmente, gran parte de los datos se 
Para Berenice Bento (2014), “el transfeminicidio sería la expresión más potente y trágica del carácter político de las identidades de género. Se asesina a la persona porque además de romper con los destinos naturales de su cuerpo-generificado, lo hace públicamente” (2) ${ }^{5}$. En el caso de las travestis y mujeres transexuales en Brasil, ellas tienen poco acceso al mercado de trabajo formal y cerca del $90 \%$ se desempeña o se ha desempeñado en la prostitución.

Desde los años 2000 los movimientos activistas trans en Brasil han reivindicado la construcción de políticas públicas en el ámbito de la salud, el trabajo y la educación. Si bien han obtenido conquistas importantes, como el acceso al Proceso Transexualizador por el Sistema Único de Salud ${ }^{6}$ (que incluye hormonoterapias y atención por parte de un equipo multidisciplinar), el uso del nombre social en ciertas instituciones públicas y privadas y el derecho al cambio del registro civil, se observan innumerables situaciones, eventos y prácticas de transfobia en espacios públicos y privados como calles, escuelas, universidades y ambientes de trabajo, entre otros.

A pesar de los riesgos, en los espacios de prostitución en las calles, travestis y mujeres transexuales del noreste al sur del Brasil ocupan diferentes territorios urbanos, incitan deseos y ponen en jaque las normatividades de género. Transgresoras de las dualidades de género niegan las representaciones de lo masculino $\mathrm{y}$, al mismo tiempo, capturan aceras, esquinas y plazas que no estaban planeadas para cuerpos que buscan placer, sexo, afecto y dinero. Como explica Andrea García Becerra (2009):

La gran mayoría de trans, travestis o transexuales rechazamos con energía la categoría "hombres” y no nos reconocemos en lo masculino. Haber sido alguna vez hombres o haber estado ubicadas en lo masculino, en nuestro caso, es algo que duele, que nos hiere profundamente y no es una forma de identidad deseable. (122)

En este texto reflexiono sobre las críticas a las normatividades de género mediante la construcción de feminidades plurales que se materializan en

colectan a partir de noticias transmitidas por los medios y en las redes sociales, en un esfuerzo realizado por instituciones y movimientos sociales LGBT. La Secretaría de Derechos Humanos de la Presidencia de la República (SDH/PR) también recoge datos en los que se utilizan tanto los registros hemerográficos como los canales oficiales (Marque 100), la Central de Atención a la Mujer, Foros de Escucha del Sistema Único de Salud (SUS) y órganos LGBT federales. El último informe de la SDH fue del 2013.

5 Mientras que el promedio de vida brasileño es de 75 años (Instituto Brasileiro de Geografia e Estatística [IBGE], la expectativa de vida de personas trans, principalmente travestis y mujeres trans, es cercano a los 35 años. 
cuerpos que no fueron designados como femeninos al nacer por los poderes biomédicos. Así pues, "si el género es algo en que la persona se torna - pero nunca puede serlo- entonces el mismo género es una especie de devenir o actividad, y no se debe concebirlo como sustantivo, como cosa sustantiva o marcador cultural estático sino más bien como una acción incesante y repetida de algún tipo” (Butler 2003, 163). Según Judith Butler (2003, 2008), las normas que regulan el "sexo" actúan de manera performativa para construir la materialidad de los cuerpos. En este sentido, para Butler la materialidad corporal puede ser creada únicamente a partir de su norma reguladora.

En nuestra investigación, lo femenino está materializado en una corporeidad trans mediante gestos, prácticas, ropas y estilos que han sido absorbidos por el dominio de la percepción (Merleau-Ponty 2006) y, al mismo tiempo, han sido transmitidos colectivamente. Basado en la teoría de Thomas Csordas (2008), el concepto de corporeidad significa pensar el cuerpo como sujeto de la cultura. Es decir, la existencia de los sujetos es corporal y el cuerpo solo existe en relación con el mundo7: "en efecto, la corporeidad es nuestra condición existencial fundamental, nuestra corporalidad (corporeality o bodiliness) en relación con el mundo y otras personas" (Csordas 2013, 292).

Sin embargo, considero que la corporalidad también puede escapar a su norma reguladora, pues, como condición de la existencia de la cultura, está en el mundo y actúa sobre él. Por esta razón, en nuestra investigación, las corporeidades trans se materializan en el ser-en-el-mundo en búsqueda de una feminidad reglada no solo por teorías locales del "ser mujer" en un modelo heteronormativo, sino que crean otras feminidades que pueden gravitar en torno a la norma reguladora y al mismo tiempo ponerla en duda.

Además, en este artículo utilizamos la perspectiva de la etnografía urbana para entender las apropiaciones de los espacios urbanos por parte de nuestras interlocutoras. Es decir, entender cómo ellas "hacen" las ciudades y producen sentidos sobre los territorios en donde viven y trabajan, más allá de los proyectos urbanísticos y de las políticas del Estado. Mediante la etnografía, podemos entender las ciudades "desde cerca y desde dentro" (Magnani 2002) y analizar las redes de relaciones y los estilos de vida. De ese modo, la etnografía urbana destaca las mallas urbanas, sus formas de sociabilidad y los usos sociales que los citadinos hacen en sus trayectorias cotidianas.

7 Según Thomas Csordas (2013), la propuesta de pensar en la corporeidad significa adoptar la perspectiva antropológica de una fenomenología cultural, fundamentada en las teorías de Merleau-Ponty, Pierre Bourdieu y Michel Foucault. El autor sugiere una agenda de discusiones (forma corporal, movilidad, experiencia sensorial, afecto, etc.) que no serán desarrolladas aquí. 
Las investigaciones que coordiné fueron realizadas por un equipo de diez estudiantes de pregrado y posgrado entre el 2015 y el 2017. El objetivo principal fue comprender formas de urbanidad a partir de los tránsitos y las movilidades de travestis y mujeres transexuales en tres regiones: la Región Metropolitana de João Pessoa en el estado de Paraíba, al noreste del país; la ciudad de São Paulo en la región sureste, específicamente en el barrio Butantã; y la triple frontera amazónica en la región del Alto Solimões, al norte, entre las ciudades de Leticia (Colombia), Tabatinga (Brasil) y Santa Rosa (Perú). En este texto me detendré solo en las dos primeras regiones citadas, para las que la información se encuentra más sistematizada y ha sido debatida colectivamente.

Al ser una investigación realizada a muchas manos, también hizo parte constitutiva de la formación de los estudiantes ${ }^{8}$ de antropología y ofreció la posibilidad de iniciarlos en la investigación de campo de una forma poco convencional. Ellos tuvieron que trabajar con un cuadro de vulnerabilidad y violencia de personas que no quieren ser identificadas y temen tanto la violencia policial como la exposición de sus imágenes en los medios y en las redes sociales. También temen que sus vidas sean reveladas y controladas, teniendo en cuenta que muchas de ellas trabajan en la prostitución de forma sigilosa, sin el conocimiento de sus familiares.

Es necesario mencionar la relación tensa de nuestras interlocutoras con el universo de la academia, que durante mucho tiempo las consideró apenas un “objeto” de investigación. Solo en los últimos años ellas comenzaron a ser protagonistas de un conocimiento propio, autoral, producido sobre sí mismas. Aunque haya un aumento de travestis, mujeres transexuales y hombres transexuales en las universidades, gran parte de esta población pasó por situaciones de violencia transfóbica en el ambiente escolar desde la niñez, lo que provocó que interrumpieran sus estudios y muchas veces abandonaran la escuela para salir de un ambiente hostil en el cual sentían que no encajaban.

En São Paulo, las indagaciones de campo se realizaron principalmente en los espacios de prostitución en el barrio Butantã, en el área próxima a la Ciudad Universitaria, donde se encuentra el mayor campus de la Universidad de São Paulo. Aunque las trabajadoras del sexo están en la región desde la construcción de la universidad, en los años 1960 y 1970, y han acompañado el proceso de transformación del barrio - actualmente ocupado por casas lujosas y edificios empresariales-, están invisibilizadas en el paisaje urbano y no existen investigaciones

8 Si bien la autora adscribe a un lenguaje inclusivo con perspectiva de género, debido a que la RCA se rige por las normas de la Real Academia Española, en este artículo se conserva el uso genérico del masculino. 
o informaciones sistematizadas sobre ellas. Solo aparecen en noticieros sesgados que narran hechos de violencia policial y robos.

Así, en el intento de conocerlas más profundamente, empezamos nuestro trabajo de campo en agosto del 2016, primero con caminatas colectivas con todo el equipo de estudiantes y, después, de forma más sistemática, en parejas y tríos en diferentes días y horarios de la semana. En alianza con la Defensoría Pública del Estado de São Paulo y con el Servicio de Asistencia Especializada DST/AIDS de Butantã, durante nuestras conversaciones y entrevistas distribuimos panfletos informativos sobre los derechos de las profesionales del sexo y sobre violencia de género, además de preservativos ${ }^{9}$.

En Paraíba, donde ya existía un acervo histórico de investigaciones realizadas entre el 2007 y el 2013 (Garcia y Nascimento 2014; Nascimento 2014) ${ }^{10}$, se realizaron indagaciones más breves en abril y mayo del 2017, con la visita del equipo a João Pessoa durante dos semanas. Como ya teníamos conocimiento de diferentes activistas trans y LGBT, el equipo pudo realizar investigación en residencias, en el Espaço LGBT - Centro Estadual de Referência dos Direitos de LGBT e Enfrentamento a Homofobia na Paraíba-y también en las calles de la ciudad y en los locales donde se practica la prostitución.

En nuestra etnografía, parto del presupuesto de que la prostitución es un importante medio de sobrevivencia o, más específicamente, un trabajo que está involucrado en el mercado del sexo que incluye intercambios materiales y simbólicos — dinero, objetos, afectos y sueños (Piscitelli 2013)—. Por medio del mercado del sexo, travestis y mujeres transexuales reinventan formas de ocupación de espacios en las ciudades que no estaban planeados para ser utilizados por minorías sexuales, transforman sus cuerpos, crean redes de afecto y sociabilidad y circulan por muchos lugares del país y del mundo. De ese modo, trabajar en la prostitución propicia alternativas económicas y sociales, aunque en las calles ellas se encuentren en situación de mayor riesgo y vulnerabilidad. Por lo tanto, mi intento no es reproducir estereotipos sobre la totalidad de los cuerpos trans sino problematizar las ambigüedades de los usos del espacio urbano por parte de travestis y mujeres transexuales en las dos regiones observadas.

9 En algunos momentos realizamos algunos registros fotográficos con aquellas que se sentían cómodas y querían ver sus imágenes y compartirlas entre amigas. No publicaremos sus fotos sin su consentimiento.

Entre el 2007 y el 2013 realicé una investigación etnográfica con travestis que se prostituyen en la carretera nacional BR 101, vía federal que bordea prácticamente todo el litoral del país, desde el sur hasta el noreste. En esta región encontramos jóvenes travestis, originarias de áreas rurales e indígenas, que se iniciaron en la prostitución en la adolescencia y se dirigen todos los días hacia puntos estratégicos como gasolineras y puestos de fiscalización vial, donde pasan choferes de camiones y otros viajeros. 
Mediante una etnografía multisituada (Marcus 1995) y a partir de la idea de la colaboración como condición de un proyecto antropológico determinado, esta etnografía se construyó movilizada por el transfeminismo, el putafeminismo, las demandas de los movimientos trans y por los escritores e investigadores trans que han producido un vasto conocimiento en los últimos años (Almeida 2012; Andrade 2012; García 2009; Jesus 2015; Lanz 2014; Missé y Coll-Planas 2010; Moira 2016; Nery 2011; Vergueiro 2015, entre muchos otros).

En Brasil, el transfeminismo empezó a ganar visibilidad en los años 2000 en las redes sociales y en los blogs de jóvenes travestis, mujeres transexuales y personas trans no binarias, que produjeron una importante red de apoyo y de producción de conocimiento sobre y para las personas trans. Inspirados en los feminismos negros y queer, han reivindicado el lugar del habla de las pensadoras trans en diferentes espacios de representación política, académica, artística, etc.

El feminismo trans es, así, un movimiento político e intelectual que contribuye de manera muy pertinente para la desconstrucción del binarismo de género y de las perspectivas esencialistas; fortalece el carácter interseccional de las opresiones; valoriza las luchas políticas y las experiencias personales de personas trans; y es un movimiento que no se reduce solo a quien desee participar, trans o cis. (Jesus 2015, 157)

Nuestra investigación también está guiada por el putafeminismo, un movimiento político que reúne a trabajadoras sexuales, investigadoras, activistas e intelectuales a escala nacional en Brasil y otros países. En líneas generales, el propósito putafeminista es respetar la autonomía de las putas reconociendo su agencia y construir propuestas políticas que vengan de sus propias experiencias y demandas concretas, tales como la problemática de la reglamentación de la profesión y los accesos a los derechos ciudadanos ${ }^{11}$. Según la Red Brasileña de Prostitutas, creada en los años noventa, las cuestiones más importantes en lo que se refiere a las políticas públicas para la prostitución son: su reglamentación, el reconocimiento del trabajo sexual como un trabajo legítimo, la promoción del acceso a la salud y la prevención del sida, el reconocimiento del trabajo sexual como derecho sexual y, finalmente, que las prostitutas puedan asumirse como tales en todos los espacios, sin prejuicios y discriminaciones.

11 En Brasil, el trabajo sexual fue reconocido como una ocupación en el año 2002 por el Ministerio del Trabajo (“Clasificación Brasileña de Ocupaciones”) pero aún no es una profesión reglamentada. 


\section{São Paulo: la ciudad de las putas}

La capital del estado de São Paulo, con aproximadamente 12 millones de habitantes, recibe centenares de travestis y mujeres transexuales provenientes de diferentes regiones de Brasil y América Latina. La región del centro, entre el Largo do Arouche y la Praça da República, es una de las más conocidas y frecuentadas, no solo por las facilidades que ofrece en servicios de prostitución, sino por el intenso comercio de ropa, productos de belleza y cosméticos, accesorios, bolsos, perfumes, etc. ${ }^{12}$. Más allá del centro, lugar con mayor proyección nacional e incluso turística, hay otras localidades importantes que forman parte de un circuito más específico de la prostitución de calle. Entre ellas está el barrio City Butantã en la zona oeste, localizado en las cercanías de la Ciudad Universitaria.

El barrio tiene cerca de 54.000 habitantes e históricamente es un área de gran circulación de personas, que alternan calles residenciales y comerciales. Una de las principales formas de trabajo en esta localidad es la prostitución callejera, donde aproximadamente entre 100 y 200 travestis y mujeres cisgénero ocupan dos avenidas paralelas a la avenida principal. Ellas son invisibilizadas y no son contabilizadas en los datos oficiales del barrio en lo que se refiere a su economía. Únicamente aparecen en los noticieros como protagonistas o víctimas de violencia, es decir, solo se tornan parte del barrio cuando el tema es la seguridad pública. Gran parte de las prostitutas que trabajan allí no viven en el área y vienen a ofrecer sus servicios todos los días en diferentes horarios: mañana, tarde y noche, los siete días de la semana. Hay también un pequeño circuito de moteles, hoteles, drive-ins, casas de masajes y casas de prostitución, donde también trabajan y circulan con sus clientes ${ }^{13}$.

Butantã, localizado a 15 kilómetros del centro de São Paulo, empezó a ser urbanizado lentamente a inicios del siglo $\mathrm{XX}^{14}$. En los años cuarenta se inició un proceso de elitización progresiva del barrio por la construcción de conjuntos residenciales. Como parte de este proyecto de urbanización, en el mismo periodo se construyó el Hipódromo Cidade Jardim que hace parte del Jóquei Clube de São

12 También es un importante circuito de ocio con casas nocturnas, saunas, hoteles, bares y cines. En el centro de São Paulo existe un Centro de Referencia y Defensa de la Diversidad vinculado al Ayuntamiento de São Paulo, que desde el 2008 atiende a profesionales del sexo, homosexuales, travestis y transexuales en situación de vulnerabilidad.

13 Algunas alternan la prostitución callejera con las casas cerradas y los sitios de internet.

14 A comienzos del siglo pasado la región todavía era rural pero ya recibía un gran aflujo de comerciantes y viajeros por estar localizada en un cruce de carreteras y por su proximidad al río Pinheiros. 
Paulo, un área de 600.000 metros que ocupa una gran parte de la larga avenida Lineu de Paula Machado. En esta época también se inició la edificación de la Ciudad Universitaria que se terminó en la década de los setenta. La presencia de las trabajadoras del sexo, travestis, mujeres transexuales y mujeres cisgénero es una constante desde la construcción del hipódromo y de la Universidad de São Paulo.

A partir del 2011 el barrio cambió su configuración debido a la inauguración de una línea de metro (y de un terminal de autobús) en la avenida Vital Brasil. Las calles se tornaron más agitadas y diferentes establecimientos comerciales se instalaron en los alrededores de la estación. Además de pequeños comercios - principalmente restaurantes y bares-, tiendas de grandes redes multinacionales de farmacia, hipermercados, ropa y concesionarios de motos comenzaron a ocupar el barrio. Desde la avenida Vital Brasil hacia la Marginal Pinheiros (una vía circunvalar en la región suroeste de la ciudad), hay un área de grandes residencias y mansiones, diversos aparcamientos y algunos bares que reciben estudiantes universitarios. Dos predios de empresas multinacionales (Odebrecht y Johnson \& Johnson), con su ostentosa arquitectura, también tienen sedes allí.

El paisaje corporal en esta región es bastante ecléctico, ofrece un escenario de universitarios de clase media, hombres con corbata, trabajadores de la seguridad privada, “cuidadores” de coches y prostitutas que dan color, olor y sonidos a un espacio aparentemente árido, de poca circulación de peatones y tránsito intenso de coches por la Marginal Pinheiros, de cuyo río solo nos acordamos por el emblemático mal olor.

En esta área, entre calles con portones enrejados, aceras monitoreadas por empresas de seguridad privada, muros altos de lujosas residencias y a la orilla del río, centenares de travestis y mujeres cisgénero hacen la calle. Durante las indagaciones de campo conversamos con cuarenta travestis y mujeres transexuales de entre dieciséis y cuarenta años, provenientes principalmente del norte y el noreste de Brasil, de ciudades como Manaos (Amazonas), Belém (Pará), Natal (Rio Grande do Norte), Recife (Pernambuco) y Fortaleza (Ceará), entre otras. Algunas son estudiantes universitarias y la mayoría han completado la escuela secundaria. Gran parte de ellas están allí desde hace poco tiempo — de una semana a seis meses-, principalmente las más jóvenes. Las de veinticinco años o más están allí hace más tiempo, entre cinco y quince años, lo cual no significa que hayan permanecido en el barrio a lo largo de todo este periodo, pues circularon por otras ciudades y regiones, incluso fuera del país. Por ejemplo, Ártemis ${ }^{15} \mathrm{de}$ veinticuatro años, pasó tres años en Santana, barrio de la zona norte de São 
Paulo, y después volvió a Belém, su ciudad de origen en Pará, donde se quedó por un año. Regresó a Santana por un año más y luego otra vez a Belém por seis meses. Y ahora estaba hace algunos días en Butantã. Nos contó que prefería trabajar en barrios de São Paulo porque estaba protegida, ya que nadie de su familia sabía qué hacía allí, lo que garantizaba su anonimato y su libertad. Deméter, con 31 años, originaria de Rondônia, también en la región norte, estaba ejerciendo la prostitución callejera en Butantã hace nueve años; durante ese periodo pasó una temporada en la ciudad de Lyon en Francia. Núbia, de veinte años, nacida en Fortaleza en Ceará, lleva dos años en el barrio y vive con otras chicas que vinieron de la misma ciudad, en un barrio cercano a la Ciudad Universitaria.

Independientemente del origen, todas tienen el mismo proyecto de movilidad social: ganar dinero en la prostitución y con esos recursos volver su cuerpo más femenino a través de intervenciones quirúrgicas y hormonales, y tener acceso a toda una red de consumo estético (servicios de belleza, ropa, zapatos de tacón, bolsos, maquillaje, perfumes, pelucas). Es un proyecto corporal y personal que incluye feminizarlo según los ideales de una estética glamorosa, redondearlo con nalgas protuberantes y senos grandes para que sea atractivo a hombres adictos al sexo. Además, también desean obtener dinero para poder viajar a Europa: Francia, España e Italia, y sentirse más reconocidas allí como ciudadanas que escapan de la transfobia y de la violencia cotidiana que sufren en Brasil.

Pero ¿cómo y por qué llegaron a Butantã? Nuestras interlocutoras afirmaron que es un lugar seguro, con clientes que pagan bien la prostitución, pero relataron diferentes formas de desplazamiento: 1) llegaron por indicaciones de amigas, 2) se informaron por las redes sociales, 3) fueron llevadas por dueñas de casas de prostitución, 4) fueron a visitar a una amiga y se quedaron, entre otras. Las historias de Diana y Luma ilustran de forma contundente este paso por São Paulo, relatado en forma de diario de campo elaborado por Alexandre Martins:

Diana usaba una blusa corta muy ancha (que mostraba sus senos cuando venteaba fuerte), que dejaba ver la barriga, y pantalones cortos. Era rubia con el pelo corto y vino desde Belém después de conocer por Facebook a otras travestis que vivían aquí en São Paulo. Después de haber identificado el esquema que debía seguir, convino con una travesti (una madama) que esta pagaría su billete de avión y ella viviría en su casa y trabajaría con ella mientras estuviera aquí en São Paulo, pagándole 50 reales diarios o 300 por semana. Según Luma, todas las travestis a las que ella conocía de Belém vinieron para São Paulo con ese esquema. [...] Luma dijo que seis meses atrás era un chico y agarró el celular para enseñarnos las fotos. Desde entonces, empezó a tomar hormonas y se había hecho una cirugía plástica de aplicación de silicona en los senos. Muy a gusto con nosotros, preguntó incluso si queríamos ver sus senos 
siliconados y se levantó la blusa allí mismo, enseñando el resultado de su cirugía. Vino a São Paulo para poder ser travesti: afirmó que su familia y sus amigos de Belém dejaron de hablar con ella a causa de eso, menos su madre que a pesar del susto por las transformaciones (tal vez por haber sido tan rápidas), todavía hablaba con ella. (Relato de campo, febrero del 2017)

Aunque sean las principales usuarias de los espacios públicos que aún quedan en el barrio - especialmente las aceras-, permanecen en lugares arborizados, oscuros, con el menor número de peatones y en los cuales resultan fácil el paso y parqueo de los coches de los clientes. De las más variadas edades, con experiencias diversas, con vestimentas y performances corporales distintas, ellas revelan los supuestos vacíos estériles de los paisajes urbanos proyectados para las élites. En los lugares de prostitución, sus cuerpos se entrelazan con los espacios urbanos propicios para la gran circulación de clientes que se mueven principalmente en coches. Así, las travestis y mujeres transexuales necesitan mostrarse y revelarse mediante ropa sexy, caminatas rítmicas que enseñen sus curvas, miradas, sonrisas y gentilezas.

En el barrio de Butantã, hay distintas formas de ocupación de los espacios urbanos por parte de las trans: algunas más jóvenes se quedan en una esquina y están siempre juntas; otras prefieren estar solas en las aceras de la Marginal Pinheiros donde pueden mostrar sus cuerpos desnudos y sus genitales fálicos; algunas se quedan más cerca de los bares para poder entrar y salir de los baños y retocar el maquillaje. Cuando los edificios comerciales y tiendas cierran sus puertas, aparecen más y más travestis y mujeres trans que iluminan la vida nocturna.

Cuerpos para quienes deseen verlos. Son, de cierto modo, errantes urbanas que se apropian de un territorio que no fue pensado ni planeado por los urbanistas para esta finalidad y producen en él prácticas autónomas, pero no necesariamente alternativas al modelo capitalista occidental, pues están profundamente inmersas en los procesos sociales y económicos de las ciudades. Por una parte, sus cuerpos trans cuestionan las heteronormatividades de género y las moralidades de los espacios públicos. Ellas se mueven por las aceras y las calles, muchas veces con poquísimas ropas, en un barrio de clase media con residencias y edificios comerciales. Por otra parte, ocupan estos territorios para atraer clientes, sentirse hermosas, sensuales y obtener dinero en intercambio por prácticas sexuales. Muchas veces, con el rendimiento financiero de la prostitución, pueden cambiar sus cuerpos, hacerse cirugías plásticas, comprar cosméticos y medicinas hormonales y, por lo tanto, sacar provecho de la industria farmacológica y médica. Por ejemplo Lilith, con un poco más de veinte años, vino de Fortaleza, 
ciudad localizada en el noreste de Brasil, y vive en São Paulo hace dos años. Con la plata ganada en la prostitución, transformó su cuerpo con cirugías plásticas estéticas: alteró la cola, los pechos y la nariz. También se puso bótox en los labios y mejillas. A ella le gusta trabajar en Butantã porque los hombres le pagan bien y hay clientes de todo tipo, estudiantes, profesores, trabajadores, entre otros.

Así pues, se construyen corpografías - una intensa relación entre cuerpo y ciudad- que "denuncian y revelan justamente lo que el proyecto urbano excluye, en la medida en que expresan usos y experiencias desconsideradas por el proyecto tradicional” (Britto y Jacques 2012, 153). En palabras de Fabiana Britto y Paola Jacques, el concepto de corpografía se contrapone a la escenografía, vinculada a un proyecto de espectacularización urbana, en el que hay una disminución de la experiencia corporal como práctica cotidiana, estética y política. Más allá de la noción de ciudad espectáculo, puro escenario capitalista sin presencia corporal, la corpografía explicita las apropiaciones cotidianas del espacio vivido y se traduce en una forma diferenciada de sentir y vivir la ciudad mediante prácticas corporales que provocan, rechazan y cuestionan la espectacularidad de las grandes ciudades contemporáneas. Así, la idea de corpografía ofrece otra perspectiva sobre el espacio urbano, pues produce una postura política en la cual el cuerpo interviene en la ciudad por medio de acciones cotidianas y performances artístico-político-culturales que cuestionan las estructuras sedimentadas del espacio público, como calles, plazas, avenidas, pasarelas, puentes, muros, automóviles, etc. En la corpografía, la ciudad está interconectada con el cuerpo en un mismo conjunto de condiciones interactivas. De ese modo, la ciudad se realiza en el cuerpo y por el cuerpo a través de movimientos y prácticas que producen acciones en el espacio urbano.

Marcia Ochoa (2011), en sus investigaciones sobre transformistas y “chicas de apariencia femenina” en la avenida Libertador en Caracas, Venezuela, muestra que la ocupación de la avenida por las trabajadoras sexuales forma parte de la lógica de este espacio urbano - construido mediante un proyecto de urbanización moderno-, y que la visibilidad trans en la ciudad está directamente relacionada con el trabajo sexual en esta avenida. La autora describe diferentes manejos y estrategias de visibilidad e invisibilidad para atraer hombres, por un lado, y escapar del control policial, por el otro. Una de las más importantes es “tener pasarela”, una forma de caminar estilizada y performativa que reorganiza el espacio y la temporalidad para que todo alrededor pueda ser observado por medio de movimientos, de ires y venires a lo largo de la avenida, en puntos estratégicos en donde puedan ser vistas y, en caso de riesgo, escapar rápidamente. Esa 
forma de caminar también se relaciona con toda una estética nacional femenina asociada con los concursos de belleza.

La pose y la pasarela crean una visibilidad para las transformistas. Les brinda legitimidad social cuando son reconocidas como mujeres glamorosas. Y aunque se conoce que las mujeres glamorosas de la avenida Libertador son transformistas, esta postura normaliza su visibilidad dentro de la estética venezolana de belleza y femineidad. Estos actos producen para ellas visibilidad y legibilidad en las calles de Caracas. (Ochoa 2011, 138)

En Butantã, cuando las travestis y mujeres transexuales llegan al barrio, caminan entre los coches todavía sin las vestimentas más cortas y sexys que serán usadas para el trabajo en la calle, y van haciendo la calle como las venezolanas. Demarcan su territorio y anuncian su llegada. "Una va elegante, pero pienso que lo que cuenta más, además de la ropa, cuando él para, la ropa es para hacerlo parar para ti. Después viene la parte en la que tú tienes que hablar con él, convencerlo de llevarte”, explica Afrodite, que se identifica como mujer trans no binaria. Hay varias técnicas corporales que pueden hacer que el cliente se detenga y las invite a entrar en su coche.

Por medio de una cuidadosa producción estético-corporal, "representan" una femineidad erotizada, con poca ropa y con parte de los senos al descubierto, o incluso mostrándose desnudas, semicubiertas con sobretodos y abrigos de cuero y de piel. Usan faldas cortas, botas de tacones finos que sobrepasan las rodillas, pantis tipo malla, vestidos de licra pegados al cuerpo que resaltan sus curvas. Aunque gran parte de ellas conozca los riesgos para la salud, también usan silicona industrial para redondear las nalgas y caderas, y aumentar los senos (Pestana et al. 2017) ${ }^{16}$.

Para travestis y mujeres transexuales, São Paulo se revela como una metrópolis con una importante centralidad que aglutina a las personas que llegan desde muchos lugares del país, del norte y del noreste, como en el caso de Butantã. No se puede afirmar que es una forma de migración contemporánea porque hay un constante ir y venir, con diversos puntos de parada, y ellas difícilmente se asientan en la capital paulista, en especial, las más jóvenes. Sin embargo, son protagonistas de la construcción de un espacio urbano moderno, que no fue proyectado para la circulación de trabajadoras sexuales que liberan perfumes, fluidos

16 En Brasil, el tema de la raza marca mucho los estereotipos de género y de sexualidad, sobre todo en lo que respecta a las mujeres, pero no lo trataré en este artículo. Destaco las investigaciones de Ana Paula da Silva (2011, 2015, 2017), que ha estudiado los procesos que cruzan raza y género para entender las imágenes sobre las prostitutas brasileñas y el tráfico sexual. 
corporales y deseos - transgresiones que brotan del asfalto como matorrales 0 malezas que no se cansan de florecer y esparcirse-. De esa manera, la capital paulista, cubierta por las hierbas transgresoras del travestismo y de la transexualidad, puede ser pensada como una ciudad-sustancia donde el cuerpo trans y la ciudad están imbricados simbióticamente.

No obstante, si por un lado la corpografía de la prostitución callejera permite que los espacios urbanos sean ocupados y utilizados de maneras disidentes por las trabajadoras sexuales, por el otro, la "ciudad-sustancia" travesti se construye también a partir de la "industria farmacopornopolítica”. Según Preciado (2008), el sexo y el trabajo sexual están en el centro de la producción farmacopornográfica mediante diferentes tipos de tecnologías que se incorporan al cuerpo: hormonas, siliconas, anabólicos, fármacos y otras drogas.

Si en la sociedad disciplinaria la arquitectura y la ortopedia sirven como modelos para entender la relación cuerpo-poder, en la sociedad farmarcopornográfica el modelo de acción sobre el cuerpo es la microprostética: el poder actúa de una molécula que viene a formar parte de nuestro sistema inmunitario, de la silicona que toma la forma de senos, de un neurotransmisor que modifica nuestra forma de percibir y actuar, la excitación sexual, la agresividad o la decodificación de nuestra feminidad o masculinidad. (67)

Así pues, travestis y mujeres transexuales en las calles del barrio de $\mathrm{Bu}$ tantã en São Paulo se movilizan para dar placer y recibir cambios monetarios, transformando sus cuerpos en objetos de deseo de los clientes y en objeto de deseo desde ellas mismas, y por medio de la transformación farmacopolítica de sus cuerpos buscan reconocimiento social, redes afectivo-sexuales y ocupación de los espacios públicos.

\section{João Pessoa: la ciudad vampira}

En São Paulo pudimos constatar una diversidad de orígenes y estilos de vida entre las travestis y mujeres transexuales, que comparten el mismo anhelo de transformación corporal y prácticas sexuales que incluyen afecto y dinero. En cambio, en João Pessoa, capital del estado de Paraíba, en la región noreste de Brasil, ellas son originarias de la misma ciudad o regiones bastante próximas. Admiran y envidian a aquellas que pudieron viajar a São Paulo, Río de Janeiro o Europa, pero temen los efectos de la violencia transfóbica y de la situación de 
crisis económica y política que invaden el país. A diferencia de otras capitales como São Paulo, salen a las calles en la noche, especialmente. Como demuestran las investigaciones de Larissa Pelúcio (2005), Dom Kulick (2008) y Hélio Silva (2007), la noche es de las travestis, quienes ocupan las aceras, plazas, casas nocturnas y bares con sus atuendos sexys, tacones altos, perfumes empalagosos, cabellos largos bien cuidados, manicura impecable y maquillajes que buscan la perfección de una cierta femineidad.

João Pessoa, con una población estimada de 811.600 personas (IBGE 2017), es una ciudad mediana que mantiene un modo de vida de pueblo centrado en las familias nucleares. A partir de los años sesenta, esta ciudad costera se fue expandiendo desde el centro histórico, donde se encuentra el río Sanhauá, hacia la playa que actualmente es un importante centro de ocio y de turismo y atrae muchos emprendimientos comerciales, restaurantes, hoteles y bares dirigidos a diferentes públicos (Oliveira 2017). Aparentemente democrática, la región de la playa - que se localiza desde Intermares, Bessa hasta Manaíra, Tambaú y Cabo Branco- tiene territorios demarcados por la circulación de habitantes, turistas y trabajadores. En la orilla, donde recibe más turistas (Manaíra, Tambaú y Cabo Branco), hay una gran área de aceras en las que al final de la tarde y los fines de semana familias de clase media se instalan con sus sillas de playa mientras los niños juegan con sus bicicletas y las parejas caminan y toman agua de coco. A diferencia de las aceras de las playas de Río de Janeiro, raramente se observan personas caminando solas en bañadores o bikinis, mostrando sus cuerpos torneados y semidesnudos. Aunque la acera está muy cerca de la arena, este pasaje demarca el desnudo y el vestido, de manera que el no cumplimiento de esta regla no dicha provoca miradas de reproche. De la misma forma, travestis y mujeres transexuales que ocupan la playa a lo largo del día en esta región también sufren miradas de extrañamiento y de condena. Según Irene, mujer transexual y estudiante universitaria de veinticinco años, hay mucha más desaprobación social en João Pessoa que en São Paulo.

Cuando fui a São Paulo, yo veía a las travestis de día andando de la mano con el novio, yo miraba así y me extrañaba y mi amigo de São Paulo dijo: “¿por qué te parece raro?”. Yo le dije: “porque allá la gente no ve eso, allá la travesti tiene que estar sola por la noche, solo la toleran de noche, de día va a tomar un autobús y cantidad de personas la miran...”. Pero a mí me gusta eso, porque me gusta que me noten, si es una travesti a quien no le gusta, se siente atemorizada por una mirada de reproche. A veces, es una mirada de admiración, mirada de coraje, son varios tipos de miradas, ¿me entiendes? A mí me importa un pimiento, si quieren mirar que miren, si me miran mucho los saludo. [...] Entonces, yo aprendí con humor, porque si te va a importar... Pienso que es eso lo que faltaría... 
Cada uno tiene derecho de ir y venir, ¿verdad? (Entrevista realizada en João Pessoa, mayo del 2017)

Así, en medio de territorios demarcados socialmente, cuando llega la noche y las familias se recogen en los espacios confortables de sus casas en los edificios de la orilla del mar, las trabajadoras sexuales ocupan las aceras de la playa de Manaíra, de 3 kilómetros de largo, y de una calle paralela, la avenida Edson Ramalho, que tiene tiendas de ropa, restaurantes turísticos, peluquerías, almacenes de suplementos alimentarios, inmobiliarias, es decir, diferentes equipos comerciales y de servicios orientados hacia la clase media y alta de la ciudad con alto poder adquisitivo. En la orilla y durante el día principalmente, al final de la playa de Cabo Branco, también hay prostitución femenina en un área estrictamente residencial donde solo circulan coches. A pesar de cierta demarcación territorial entre mujeres cisgénero y travestis, se puede encontrar a unas y otras en diferentes lugares, lo que evidencia una cierta tolerancia y convivencia mutuas, que no observamos en el barrio Butantã en São Paulo. Además de la playa, también practican la prostitución de calle en la avenida Epitácio Pessoa, la principal avenida que conecta la playa con el centro, en la Lagoa Sólon de Lucena (en el centro comercial) y en calles del centro histórico.

Durante las investigaciones de campo, realizadas en abril y mayo del 2017, estimamos la circulación de aproximadamente cincuenta travestis y mujeres transexuales, incluyendo las que trabajan en la playa y en el centro. Hay una variedad de estilos de vida: algunas son estudiantes universitarias, peluqueras, manicuristas, costureras, actrices de teatro y hacen de la prostitución una forma adicional de renta. En comparación con las que se encuentran en São Paulo, tienen el mismo proyecto de movilidad social y transformación corporal, pero gran parte de ellas son paraibanas o de estados cercanos, como Rio Grande do Norte y Pernambuco, y no necesariamente ven en São Paulo una opción para vivir, debido a la violencia de la que pueden ser víctimas allí17. Mencionan a São Paulo como una posibilidad para la realización de cirugías plásticas a precios más accesibles, pero temen ser víctimas de violencia, situación que es extremadamente explotada por los noticieros televisivos y que refuerza la imagen de esta ciudad como una de las más violentas de Brasil. Ellas creen que en São Paulo hay más riesgos de sufrir transfobia, aunque en términos comparativos, considerando las dimensiones de São Paulo y de Paraíba, el índice de transfobia — proporcional al

17 Algunas ya estuvieron en São Paulo trabajando en la prostitución pero decidieron volver a su ciudad de origen, pues creen que el costo de vida en la capital paulista es muy alto, lo que no significa que no pasen pequeñas temporadas allí para hacer compras y cambiar sexo por dinero. 
tamaño y la población- es mayor en esta última. Según el informe de violencia homofóbica de la Secretaría de Derechos Humanos de la Presidencia de la República del 2013, São Paulo ocupa el primer lugar en el número de homicidios de personas LGBT, con un 8,8\% del total de los 251 reportados en términos absolutos, mientras que Paraíba está en el quinto lugar, con el 6,8\%.

En relación con la ocupación del espacio urbano, las travestis y mujeres transexuales que se prostituyen utilizan las calles y aceras en los momentos en que la ciudad parece estar dormida. João Pessoa no tiene una vida nocturna pulsante, con presencia de bares y casas nocturnas abiertas todos los días de la semana donde circulen jóvenes y turistas. El ocio nocturno ocurre principalmente al final de la semana, de jueves a domingo. En el momento en que la ciudad duerme, los clientes pueden circular libremente por las calles de la orilla o del centro sin ser vistos, lo que garantiza su anonimato. Así, la noche es propicia para hombres - muchos de ellos casados y con una relación heterosexual estable-, travestis y mujeres transexuales en busca de placer, sexo y dinero.

La ocupación de las calles de la playa por las trabajadoras del sexo acompaña el proceso de urbanización de la región, que se inició en los años cincuenta, se intensificó en los años setenta y siguió hasta la década de los noventa, con la construcción de edificios para las clases medias y altas, que hasta entonces habitaban el centro de la ciudad alrededor del río Sanhauá, donde estaba el polo financiero y de negocios. El proceso de verticalización de las áreas de la playa, impulsado por la inversión inmobiliaria y por los sistemas de financiación habitacional, atrajo también a mujeres y travestis debido a la cada vez mayor circulación de dinero, coches y conductores. Paradójicamente, ellas actúan en barrios marcados por la segregación socioespacial donde las élites no se intimidan al demostrar sus prejuicios transfóbicos y repudiar la prostitución, pero también son lugares en donde pueden encontrar clientes que pagan la prostitución con valores más altos.

A su vez, en el centro de la ciudad, la prostitución travesti ocurre en dos calles paralelas (Diogo Velho y Rodrigues de Aquino) próximas al mercado central, lugar de gran circulación de personas durante el día por la variedad de comercio, almacenes de productos alimenticios, electrónicos, tiendas de departamento y bancos. En esta área también están localizadas la Cámara Municipal de João Pessoa, el Tribunal de Justicia de Paraíba y una sede del Ministerio del Trabajo. Pero a la puesta del sol, cuando se cierran todos los establecimientos, las calles son ocupadas solo por trabajadoras del sexo y personas sin hogar. Con las vías prácticamente desiertas, ellas pueden estar en los espacios públicos que les son silenciosamente negados durante el día y tienen la posibilidad de darles olores, sonidos 
y gestos envolventes. Esas ocupaciones, transgresoras aun, no son siempre bien recibidas. Recientemente conocimos la noticia de que una travesti joven y negra, que también estudiaba en la Escuela Técnica en Enfermería, fue asesinada a tiros por un cliente después de tener sexo, lo que suma un nuevo crimen transfóbico en Paraíba. Una de las problemáticas fundamentales en relación con los casos de transfeminicidio cometidos por hombres, que generalmente se identifican como heterosexuales, habla de las tensiones creadas en torno de la representación hegemónica de la masculinidad. Practicar relaciones sexuales con personas femeninas, que poseen atributos corporales fálicos y que pueden actuar como pasivas y activas, penetradoras y penetrables, que borran las fronteras de género y de sexualidad, provoca sentimientos ambiguos de profundo deseo y rechazo. Este último se puede manifestar en crímenes violentos, pues a las víctimas se les prohíbe una existencia considerada moralmente aceptable, cuyas vidas son negadas.

Por fuera del centro, muchas travestis ocupan las afueras de João Pessoa y trabajan en otros territorios urbanos, como gasolineras y puestos de control fiscal (la BR 101), que están al margen de una carretera federal, donde hay una gran circulación de coches y camiones. Esta carretera conecta João Pessoa con otras capitales, como Recife al sur y Natal al norte, que disponen de un amplio mercado del sexo. En nuestra investigación, conocimos a dos jóvenes travestis que vivían en Mamanguape, una pequeña ciudad cortada por la autopista BR 101, en la región metropolitana de João Pessoa. Ariel y Dalila compartían una habitación y empezaban a hacer trabajos sexuales en gasolineras y bares al borde de la carretera. Todas las noches, las amigas viajaban un promedio de 30 kilómetros para atender camioneros - sus clientes preferidos-, en un puesto fiscal próximo al estado de Rio Grande do Norte, frontera con Paraíba.

La región de Mamanguape hace parte de una red en el mercado del sexo del noreste que incluye capitales y pequeñas ciudades ubicadas en espacios de gran circulación de personas, como carreteras, avenidas, calles, estaciones de autobuses, etc. Son territorios fronterizos que desvelan otras ciudades, extraoficiales, invisibles, donde existen y resisten travestis y otras trabajadoras sexuales. En los trabajos de campo, las acompañamos en sus trayectos cotidianos y las escuchamos soñar con sus proyectos de viaje hacia otras ciudades. En efecto, pasados algunos meses desde que la conocimos, Dalila, de diecinueve años, se mudó a Recife, una gran capital, pues había sido invitada a vivir en una casa de prostitución por una travesti mayor. Ella deseaba ganar más dinero para transformar su cuerpo, practicarse cirugías plásticas y hacerse más femenina. Sin embargo, a los quince días, fue brutalmente asesinada; un terrible transfeminicidio que se suma a las estadísticas. 
Teresa Caldeira (2000) muestra que en Brasil hay una estricta relación entre violencia, cuerpo y rechazo de los derechos civiles. Los cuerpos de los migrantes, los pobres, los negros y las minorías sexuales son percibidos como susceptibles de varias intervenciones; pueden ser manipulados, torturados e invadidos, como si no hubiera una noción de derecho individual para todos los ciudadanos brasileños. Para la autora, esta cuestión está en el centro de la discusión sobre la democracia disyuntiva brasileña, en la que a partir de la Constitución de 1988 hubo una garantía de los derechos políticos y sociales que no se vio acompañada de la ampliación de los derechos civiles.

Se concibe el cuerpo como locus de punición, justicia y ejemplo en Brasil. Él es concebido por la mayoría como lugar apropiado para que la autoridad se afirme a través de la imposición del dolor. En los cuerpos de los dominados —niños, mujeres, negros, pobres o supuestos criminales-aquellos en posición de autoridad marcan su poder buscando, por medio de la imposición del dolor, purificar las almas de sus víctimas, corregir su carácter, mejorar su comportamiento y producir su misión. (370)

De ese modo, los cuerpos travestis y trans no tienen reconocimiento social y político de su integridad; en particular, por sus atrevimientos y formas transgresoras que adquieren visibilidad en el paisaje urbano, causan "perturbación" y se vuelven desprotegidos. Para Caldeira, el lenguaje de la violencia contra los grupos minoritarios impone principios morales a través del miedo y del dolor y pretende "corregir" sus comportamientos mediante la marcación corporal, que se puede entender de forma unívoca más allá de las palabras y de la racionalidad.

Así mismo, las interlocutoras de nuestras investigaciones resisten a estos procesos de exclusión y violencia e insisten en ocupar espacios donde las normas reguladoras de la ciudad son más hegemónicas. Con sus cuerpos disidentes, pero producidos y ordenados por la industria farmacopornográfica (Preciado 2008), ponen en evidencia la centralidad del sexo y de la excitación en la sociedad contemporánea que rechaza y desea a la vez prácticas que mezclan fronteras de género, sexualidad, posiciones sexuales, estilos de vida y de creación de nuevas territorialidades en las ciudades.

$\mathrm{El}$ asesinato de Dalila, que representa muchos casos de transfeminicidio de jóvenes travestis en Brasil cometidos por hombres en las calles, movilizó a nuestro equipo de investigación a empezar una aproximación con el movimiento trans en Paraíba e iniciar un largo proyecto de intervención social en colaboración con la Associação de Travestis e Mulheres Transexuais da Paraíba (Astrapa). Organizamos exposiciones fotográficas, seminarios, encuentros LGBT y 
performances en los espacios de la universidad y en los espacios públicos de João Pessoa, como plazas, calles y aceras.

En Astrapa conocimos la actuación de algunas activistas, con distintas historias de vida, como Fernanda Benvenutty, quien ha ganado visibilidad nacional en el movimiento LGBTI brasileño. Fernanda es técnica en enfermería y trabaja hace muchos años en hospitales públicos, principalmente con mujeres embarazadas. Participa de articulaciones y consejos nacionales y fue candidata al Concejo Municipal y diputada estadual. No ha ganado las elecciones pero continúa la lucha por los derechos de las personas trans en todo el país. La afirmación política de las travestis y mujeres transexuales ha demostrado una estrategia pública de reconocimiento en un país donde hay pocas posibilidades para las experiencias transitivas de ser y estar en el mundo. Para las activistas, la prostitución representa la constatación de un escenario cotidiano que hace parte de las trayectorias de vulnerabilidad económica y social de personas trans femeninas, vidas cargadas de prejuicios y estigmas.

Por supuesto, los cuerpos y las experiencias trans son infinitamente diversos. Hay espacios de resistencia y de respeto que se producen en movimientos sociales, centros de estudio, organizaciones no gubernamentales, instituciones, lugares de sociabilidad, en territorios que permiten vivir más allá de los modelos normativos heterosexuales hegemónicos. Pero, en Brasil, son pocos aún.

\section{Corpografías divergentes: impresiones finales}

Si se perciben los cuerpos trans como susceptibles de ser invadidos y corregidos por las normatividades hegemónicas del otro, ellos a su vez traspasan sus propios límites y ofrecen nuevas perspectivas para entender la vida. Según Manuel Roberto Escobar (2013), se puede comprender el cuerpo trans como un cuerpo barroco, cuyos movimientos van más allá de sus propios objetivos, que escapan a la homogeneidad del ethos capitalista.

El cuerpo trans, en tanto cuerpo barroco, es, por sobre todo, un cuerpo hipertélico. Al contrario del cuerpo dócil, no es un cuerpo acabado, dado, sino que asume transformaciones que superponen una y otra vez imágenes. Por tanto, participa de la concepción del cuerpo hiperestésico, abierto y sin fronteras, susceptible de intervenciones desde lo externo. (144) 
De acuerdo con este autor, el cuerpo trans - masculino o femenino- es puro exceso de significado que se transforma por medio de intervenciones estéticas, quirúrgicas y farmacológicas, atento a todos los detalles, ornamentos y gestos pensados para ser revelados, encubiertos o disfrazados. Escobar argumenta que la metáfora del barroco evidencia especificidades latinoamericanas de resistencia corporal y de formas de sobrevivencia de las personas trans. Justamente por traspasar fronteras, sus transformaciones afectan los mundos que las rodean y, puedo afirmar, interfieren también en los espacios urbanos y en las ciudades por donde circulan.

En las dos regiones descritas en este artículo, al noreste y sureste de Brasil, se observaron distintos modos de ocupación y de circulación por el espacio urbano de travestis y mujeres transexuales. Las ciudades deseadas por nuestras interlocutoras son aquellas que les ofrecen mayores posibilidades de consumo, de acceso a servicios de salud y de la industria farmacológica y cosmética, de ampliación de las redes de sociabilidad y afecto, y de conocimientos cosmopolitas sobre cuerpo, belleza, dinero, ocupación del espacio público y variadas formas de violencia urbana.

Ese modo de ocupación urbana está fragmentado y no se fija necesariamente en una única ciudad. Por lo tanto, hay un proceso de desterritorialización en el sentido de un constante movimiento entre ciudades y puntos de trabajo, de rupturas con las normatividades de género y de tensiones con sus familias de origen. Y, al mismo tiempo, un proceso de reterritorialización en el propio cuerpo, que adquiere materialidad y vida en tránsito, a lo largo de caminos y no exactamente en algún lugar (Ingold 2015). Así, la existencia trans es vida en el sentido propuesto por Tim Ingold, como la capacidad de traspasar sus propios destinos, un movimiento de apertura y de líneas de fuga, no de cierre. Y esta vida se hace por senderos y lugares, dejando rastros. Estos rastros dejados por las trabajadoras sexuales en las ciudades brasileñas deben ofrecer otras perspectivas sobre las ciudades, a partir de una postura política en la cual el cuerpo interviene en el espacio urbano produciendo una corpografía trans que cuestiona las estructuras sedimentadas del espacio público.

Para finalizar, las ciudades de las travestis y mujeres transexuales brasileñas que se prostituyen están en constante devenir (Deleuze y Guattari 1997), siempre en plural, atravesadas por el deseo y por la materialidad corpórea y espacial. Esa idea trae consigo movimientos de desterritorialización, territorialización y reterritorialización, movilidades corpóreas y extensivas que se hacen por relaciones simbióticas y de contagio en un proceso no lineal, no unitario, sino molecular y múltiple. 
Devenir es, a partir de las formas que uno tiene, del sujeto que se es, de los órganos que se posee o de las funciones que se rellene, extraer partículas, entre las cuales instauramos relaciones de movimiento y reposo, de velocidad y lentitud, las más próximas de aquello que estamos en vías de tornarnos, y a través de las cuales nos tornamos. Es en ese sentido que el devenir es el proceso del deseo. (Deleuze y Guattari 1997, 55)

Como proceso del deseo, el devenir-ciudades irrumpe como malezas en medio del proyecto urbanístico de las ciudades planeadas, recalificadas y gentrificadas (Jacques 2001). Brotan en el bordillo de las aceras desiertas, en las orillas de los ríos contaminados, proliferan en plazas que no lograron ofrecer actividades de ocio para “familias de bien”. Subsisten entre los muros de los equipamientos urbanos fallidos y oficinas públicas y se mueven entre rejas y garitas de seguridad que insisten en controlar el derecho de ir y venir.

Tal vez pudiéramos imaginar espacios urbanos en los cuales esas formas de vida rizomáticas fueran respetadas y que cuerpos-personas trans, travestis, transexuales, no binarios, transformistas, locas, chicas, putas, marimachos, butches, maricas, queers, gais, mujeres negras pudieran volver a dar color a un Brasil repleto de ciudades-gris.

\section{Referencias}

Almeida, Guilherme. 2012. “'Homens trans”: novos matizes na aquarela das masculinidades?”. Revista Estudos Feministas 20 (2): 513-523. https://doi.org/10.1590/S0104-026X2 012000200012

Andrade, Luma. 2012. "Travestis na escola: assujeitamento e resistência à ordem normativa”. Tesis de doctorado en Educación, Universidade Federal do Ceará, Fortaleza.

Bento, Berenice. 2014. "Brasil: o país do transfeminicídio". Centro Latino-americano em Sexualidade e Direitos Humanos (CLAM). http://www.clam.org.br/uploads/arquivo/trans feminicidio_berenice_bento.pdf

Britto, Fabiana y Paola Jacques. 2012. “Corpo e cidade, complicações em processo”. Revista da Universidade Federal de Minas Gerais 19 (1-2): 142-155. https://www.ufmg.br/revistaufmg/pdf/REVISTA_19_web_142-155.pdf

Butler, Judith. 2003. Problemas de gênero. Río de Janeiro: Civilização Brasileira.

-. 2008. Cuerpos que importan. Buenos Aires: Paidós.

Deleuze, Gilles y Félix Guattari. 1997. Mil platôs. Capitalismo e esquizofrenia 2. Vol. 4. São Paulo: Editora 34. 
Escobar, Manuel Roberto. 2013. "La politización del cuerpo: subjetividades trans em resistencia”. Nómadas 38: 133-149. https://www.redalyc.org/articulo.oa?id=105127475009

García Becerra, Andrés. 2009. “Tacones, siliconas, hormonas y otras críticas al sistema sexgénero. Feminismos y experiencias de transexuales y travestis”. Revista Colombiana de Antropología 45 (1): 119-146. http://www.redalyc.org/pdf/1050/105012398005.pdf

Garcia, Loreley y Silvana Nascimento. 2014. Pitfalls of Desire. A Study about Rural and Indigenous Juvenile Prostitution in the Northeast of Brazil. Saarbrücken: Lambert Academic Publishing.

Ingold, Tim. 2015. Estar vivo. Ensaios sobre movimento, conhecimento e descrição. Petrópolis, Río de Janeiro: Vozes.

Jacques, Paula. 2001. A estética da ginga-a arquitetura das favelas através da obra de Helio Oiticica. Río de Janeiro: Casa da Palavra.

Jesus, Jaqueline. 2015. Transfeminismo: teorias e práticas. Río de Janeiro: Metanoia.

Kulick, Don. 2008. Travesti: prostituição, sexo, gênero e cultura no Brasil. Río de Janeiro: Fiocruz.

Lanz, Leticia. 2014. "O corpo da ropa. A pessoa transgênera entre a transgressão e a conformidade com as normas de gênero”. Disertación de Maestría en Sociología, Universidade Federal do Paraná, Curitiba.

Magnani, José Guilherme. 2002. "De perto e de dentro: notas para uma etnografia urbana”. Revista Brasileira de Ciências Sociais 17 (49): 11-29. http://dx.doi.org/10.1590/S010269092002000200002

Marcus, George. 1995. "Ethnography in/of the World System: The Emergence of Multi-Sited Ethnopgraphy”. Annual Review of Anthropology 24: 95-117. https://doi.org/10.1146/annurev. an.24.100195.000523

Missé, Miquel y Gerard Coll-Planas, eds. 2010. El género desordenado. Críticas en torno a la patologización de la transexualidad. Barcelona; Madrid: Egales.

Moira, Amara. 2016. E se eu fosse puta. São Paulo: Hoo Editora.

Nascimento, Silvana. 2014. "Corpo-afeto, corpo-violência: experiências na prostituição de estrada na Paraíba”. Revista Ártemis 18 (1): 69-86. http://doi.org/10.15668/1807-8214/arte mis.v18n1p69-86

Nery, João. 2011. Viagem solitária: memórias de um transexual 30 anos depois. São Paulo: Leya.

Ochoa, Marcia. 2011. "Pasarelas y 'perolones”: mediaciones transformistas en la avenida Libertador de Caracas”. Revista de Ciencias Sociales 39: 123-142. https://doi.org/10.17141/ iconos.39.2011.749

Oliveira, Thiago. 2017. Sobre o desejo nômade. Pessoa, corpo, cidade e diferença no universo da pegação. Río de Janeiro: Multifoco.

Pelúcio, Larissa. 2005. "Na noite nem todos os gatos são pardos: notas sobre prostituição travesti”. Cadernos Pagu 25: 217-248. http://dx.doi.org/10.1590/S0104-83332005000200009

Pestana, Thiago, Flavia do Bonsucesso Teixeira, Claudia Renata dos Santos Barros, Ricardo Barbosa Martins, Gustavo Santa Roza Saggese, Daniel Dutra de Barros y 
Maria Amelia de Sousa Mascena Veras. 2017. "Silicone líquido industrial para transformar o corpo: prevalência e fatores associados ao seu uso entre travestis e mulheres transexuais em São Paulo, Brasil”. Caderno de Saúde Pública 33 (7). http://doi. org/10.1590/0102-311X00113316

Preciado, Paul B. 2008. Texto yonquie. Madrid: Espase Calpe.

Silva, Ana Paula da. 2011. “'Cosmopolitismo tropical': uma análise preliminar do turismo sexual em São Paulo”. En Gênero, sexo, amor e dinheiro: mobilidades transnacionais envolvendo o Brasil, organizado por Adriana Piscitelli, Glaucia de Oliveira Assis y José Miguel Nieto Olivar, 103-140. Campinas: Coleção Encontros, PAGU; Núcleo de Estudos de Gênero, Unicamp.

—. 2015. "Trabalho sexual: entre a conquista de direitos e o processo de vitimização". Novos Debates 2: 223-232. http://novosdebates.abant.org.br/index.php/numero-atual/forum -v2n1/145-v2-n1/forum-v2n1/193-trabalho-sexual-entre-a-conquista-de-direitos-e-o-pro cesso-de-vitimizacao

Silva, Ana Paula da y Thaddeus Gregory Blanchette. 2017. "Por amor, por dinheiro? Trabalho (re)produtivo, trabalho sexual e a transformação da mão de obra feminina”. Cadernos Pagu: 1-35. http://doi.org/10.1590 / 18094449201700500019

Silva, Hélio. 1993. Travesti-a invenção do feminino. Río de Janeiro: Relume Dumará/ISER.

-. 1996. Certas cariocas-travestis e vida de rua no Rio de Janeiro. Río de Janeiro: Relume Dumará.

-. 2007. Travestis-entre o espelho e a rua. Río de Janeiro: Rocco.

Vergueiro, Viviane. 2015. "Por infexões decoloniais de corpos e identidades de gênero inconformes: uma análise autoetnográfica da cisgeneridade como normatividade”. Disertación de Maestría en el Área Muldisciplinar Cultura y Sociedad, Universidade Federal da Bahia, Salvador. 